\title{
An Ethnographic Study on the Non-Material Impacts of the Educated Youth Program
}

\author{
Chloe Yim ${ }^{1}$ and Kathryn Upton\# \\ ${ }^{1}$ Independence High School, San Jose, CA, USA \\ \#Advisor
}

$\underline{\text { ABSTRACT }}$

In a movement that led to over a million civilian deaths and the persecution of millions more, the Chinese Cultural Revolution mobilized all aspects of state in order to upheave traditional hierarchy and maintain a Maoist regime. During this time, under the Educated Youth Program, nearly 17 million students of varying societal backgrounds moved to rural locations to develop "proper" values and skills. Through a qualitative ethnographic case study, twelve narrative interviews conducted with participants of the program, representing multiple regions in China, were examined under the principles of thematic analysis in order to discover overarching themes about the immaterial impacts that occurred as a result of this wide-scale emigration and whether these changes were positive or negative. Data indicated that (1) because of the rural environment and hard-working people around them, many participants gained perseverance, and (2) increased interactions with those of ethnic and economic different backgrounds led to greater acceptance of others. The findings of the study suggest that the Educated Youth Program was ultimately beneficial for its participants in regards to their overall life. These results help build a more comprehensive understanding about the impacts of rural education in China through the direct incorporation of participants' perspectives.

\section{Historical Context}

From the years 1966 to 1976, the final extension of Mao Zedong's rule manifested into the Chinese Cultural Revolution, a sociopolitical movement that would culminate into a strong transformative force, drastically impacting all aspects of Chinese society up to the present time. The main purpose of the Cultural Revolution was to establish a classless society and upheave traditional hierarchy. ${ }^{1}$ According to Zhou and Hou, researchers from Duke University, a highlighting characteristic of this time was the strength of the state; there was no doubt when it came to government notions. ${ }^{2}$ Intolerable actions were conducted in order to strengthen the Maoist regime. This strict movement led to the persecution of nearly 30 million citizens in some form, resulting in an astounding 1.5 million fatalities. ${ }^{3}$ It is reflected upon as one of the worst periods of Chinese history.

One notable effort to achieve the pure, equal utopian society propagandized by Mao was the mass closure of schools and universities, leading to this age cohort becoming known as the "lost generation" in reference to their lost opportunities. ${ }^{4}$ An immediate result of this was the rise of a new state-approved institution, which aimed to teach

\footnotetext{
${ }^{1}$ Deng, Zhong, and Donald J. Trieman. "The Impact of the Cultural Revolution on Trends in Educational Attainment in the People's Republic of China." The American Journal of Sociology, vol. 103, no. 2, 15 Feb. 2013, pp. $391-428$.

${ }^{2}$ Zhou, Xueguang, and Liren Hou. "Children of the Cultural Revolution: The State and the Life Course in the People's Republic of China.” American Sociological Review, vol. 64, no. 1, February 1999, pp. 12-36.

${ }^{3}$ Walder, Andrew G, and Yang Su. "The Cultural Revolution in the Countryside: Scope, Timing and Human Impact.” The China Quarterly, no. 173, 2003, pp. 74-99. JSTOR, www.jstor.org/stable/20058959?seq=1.

${ }^{4}$ Chen, Yixin. "Lost in Revolution and Reform: The Socioeconomic Pains of China's Red Guards Generation,
} 
students "practical skills" over traditional coursework through rural education; this was promoted under various "Up to the Mountains, Down to the Countryside" movements. ${ }^{5}$ Thus, participants of this education are often referred to as the "Sent-Down" students or zhiqing. This sustained practice of sending clustered urban youth to rural agricultural environments to encourage cultural and ideological reform across geographic locations is now academically termed as the "Educated Youth Program".

Although some students did volunteer, adolescents at the time received little to no options regarding enrollment due to societal and governmental pressures. In totality, nearly 17 million youth in China participated in this program, making this phenomenon the only instance of wide-scale emigration due to education ever recorded. ${ }^{6}$ The program was physically draining, often forcing participants to work long hours, 7 days a week, with little focus on actual curriculum. ${ }^{7}$ Consequently, as participants reintegrated into society at the end of the Cultural Revolution, pursuing higher education and joining the workforce, society was fundamentally impacted by the unprecedented experiences endured by this generation. Attempts to map out this myriad of changes reveal the complex relationship between personal values, interactions, and experiences that entangle Post-Cultural Revolution China.

\section{Literature Review}

The Educated Youth Program in particular tends to garner a wide variety of opinions from the academic community, most likely due to the extremities of its circumstances. Experts often dispute the true impact of the education provided by the program, as how these impacts should be measured and interpreted are not consistent throughout the academic field. Common measures used in modern literature include but are not limited to: higher-educational attainment, annual income, and physical wellness. This literature review will discuss three studies in attempts to capture the variation of considerations in this field.

One commonly held position is the lack of an overall significance due to the environment rural education was generated in. Professor Fan, from the University of Michigan, asserts that despite the Educated Youth Program certainly being a disruptive occurrence, there are no long-lasting or drastic impacts as a result of the program specifically. ${ }^{8}$ Fan utilized a broad-surveying method to gather data in selected cities in order to evaluate the research question through two quality of life measures: employment and health. In terms of employment, Fan notes the "general lack of opportunities throughout the Cultural Revolution decade", refuting the association of employment as a valid measure of the Educated Youth Program as regardless of participation in the program, most citizens saw changes in employment trends. ${ }^{9}$ The program may have provided some life skills, but these skills become negligible when considered with the employment field at the time. Fan also found insignificant divisions in health. Overall, Fan concludes the impacts of the Educated Youth Program are insignificant since youth who participated lacked greater understanding regarding the magnitude of change surrounding them.

In response, Professor Yu Xie and his team from the University of Michigan critiques the surveying method utilized by Fan, as well as several older studies, because "youth who were sent down may have stayed in the

1966-1996." Journal of Contemporary China, vol. 8, no. 21, 2013, pp. 219-239.

${ }^{5}$ Ebrey, Patricia Buckley (2005). China: A Cultural, Social, and Political History (1st ed.). Wadsworth Publishing. p. 294. ISBN 978-0618133871.

${ }^{6}$ Yihong, Pan. "An Examination of the Goals of the Rustication Program in the People's Republic of China." Journal of Contemporary China, vol. 11, no. 31, 2 Aug. 2010, pp. 361-379.

${ }^{7}$ Bernstein Thomas. Up to the Mountains and Down to the Villages: The Transfers of Youth from Urban to Rural China. New Heaven: Yale University Press; 1977.

${ }^{8}$ Fan, Wen. "Children of the Chinese Cultural Revolution: Disrupted Education, Send-Down Experiences, and Subsequent Health." Conservancy.UHN, University of Minnesota Digital Conservancy, June 2015, http://conservancy.umn.edu/handle/11299/175433.

${ }^{9}$ Ibid. 87. 
countryside or gone to other cities, making the comparison... in selected cities problematic". ${ }^{10}$ Alternatively, Xie collected data through a three-city survey method measuring higher-education attainment impacts under a simple fixedeffects model. Through this methodology, Xie obtained statistically significant findings regarding the Educated Youth Program. The research asserts that not only did the program fail to benefit youth directly, there is also evidence suggesting a negative influence, observed under what the study concludes to be "an example of human resilience, in which people who suffer difficult or traumatic circumstances [found] ways to... avoid lasting harm". ${ }^{11}$ Another interpretation proposed by the researchers was that "youth who stayed in cities also faced dire circumstances for socioeconomic advancement", making it probable that the program served as an equalizer for employment by taking away opportunities. ${ }^{12}$ The Xie study contrasts Fan's by arguing that despite the overall circumstances of the Chinese Cultural Revolution, the Educated Youth Program still lead to unique impacts on its participants that are not experienced by other citizens.

Similarly, Professor Weina Zhou, in her thesis for the Department of Economics at Dalhousie University, concludes statistically significant findings through the use of 1968 government-collected data. Through a unique comparison between the Educated Youth Program and military service, Zhou asserts that the "experience combined with financial support has [had[ a positive effect on educational attainment". ${ }^{13}$ Furthermore, this trend led to a substantial average increase in incomes for participants as they joined the workforce. ${ }^{14}$ This comparison contrasts the analysis of both Xie and Fan who declare the Educated Youth Program as a largely unprecedented phenomenon, one with no accurate juxtaposition. This distinctive perspective may be due to the fact that researchers who conducted surveys may inadvertently follow and sample from different populations than those observed by Zhou and government data. Thus, Zhou gives a different perspective through variant data.

\section{Gap in Research}

Although Fan, Xie, and Zhou's research have built an extensive understanding concerning the measurable impacts of the Educated Youth Program, no study has been directed towards uncovering immaterial impacts. The majority of literature focuses on establishing quantitative categories, including research that utilizes surveying methods. The current gap in research fails to evaluate impacts such as shifts in personal values or psychologies that are commonly considered in regards to education ${ }^{15}$ — due to the lack of qualitative perspectives on the Educated Youth Program. Thus, a deeper insight into the Educated Youth Program can be achieved through investigation utilizing qualitative methodologies.

Furthermore, a large majority of research, such as the one conducted by Professor Zhou, uses governmentcollected data to draw conclusions which may inadvertently discriminate against certain groups of people. In fact, much of the research “in national archives on topics such as the 'sent-down youth' ... remains reserved for the party's own internal historians", making it unlikely that only using available government data will lead to generalizable

\footnotetext{
${ }^{10} \mathrm{Xie}, \mathrm{Yu}$, et al. "Did Send-down Experience Benefit Youth? A Reevaluation of the Social Consequences of Forced Urban-Rural Migration during China's Cultural Revolution.” Social Science Research, vol. 37, no. 2, June 2008, pp. 686-700. National Center for Biotechnology Information, www.ncbi.nlm.nih.gov/pmc/articles/PMC2597845/.

${ }^{11}$ Ibd. 17.

12 Ibd. 4

${ }^{13}$ Zhou, Weina. "How Does a Traumatic Experience During Youth Affect Life Later ? The Long-Term Impact of the Send-Down Program During the Chinese Cultural Revolution." Semantic Scholar, DalHousie University, August 2013, pp. 4. https://www.semanticscholar.org/paper/How-Does-a-Traumatic-Experience-During-Youth-AffectZhou/733526af03caa40a16094da74437fffade096c84

${ }^{14}$ Ibd. 12

${ }^{15}$ Hyman, H. H., \& Wright, C. R. (1979). Education's Lasting Influence on Values. American Journal of Education, 88(1), 113-119. https://doi.org/10.1086/443505
} 
findings. ${ }^{16}$ Moreover, as Researcher Gao from the University of Adelaide asserts, the reading of secondary data for the Chinese Cultural Revolution may be uniquely problematic as through a cultural perspective, there has been a noted discrepancy between the interpretations of citizens, the government, and foreign researchers, leading to a need for more fieldwork on this topic ${ }^{17}$. This study will aim to diminish this discrepancy through the reliance on firsthand accounts and interviews by incorporating participants more directly in the study.

Additionally, according to Kanbur and Zhang, from Cornell Policy Research, regional inequality in China today can be explained by the varying impacts of the Cultural Revolution and differences are important to account for in analysis. ${ }^{18}$ The few researchers who do focus on collecting their own data are still generally contained within one region of China, even if samples are taken from multiple cities, as seen in the criticism of Fan. Research which takes a holistic geographic approach, with equal representation of various regions of China, is necessary for more accurate and generalizable conclusions on this topic.

\section{Methodology}

The methodology focused on answering the question: Did specific experiences in the Educated Youth Program have a lasting positive or negative impact on participants' lives overall?. Specifically, through a qualitative ethnographic case study, this research attempts to uncover the immaterial impacts of the Educated Youth Program which participants carried with them beyond the program itself. An ethnographic study "focuse[s] on building arguments about cultural, group, or community formation or examining other sociocultural phenomena", ${ }^{19}$ while case study refers to the use of multiple units of data, in this instance the evaluation of multiple participants. ${ }^{20}$ This methodology was chosen to fill the current gap in research by bringing the perspectives of participants directly into the study as evidence, avoiding generalizations and secondary data. It is important to note that the research question makes the key assumption that there are lasting immaterial impacts from the Educated Youth Program. Based on the extensive number of measurable impacts and differences observed through the literature review, I justified that the existence of immaterial impacts was plausible. To begin, I originally hypothesized that the Educated Youth Program would have an overall positive implication due to its focus on teaching values and life skills. To test this hypothesis, I collected narrative interviews and performed thematic analysis.

Various fields have utilized in-depth interviews and thematic analysis in order to incorporate qualitative perspectives when analyzing societal trends in Post-Cultural Revolution China. For example, Nagata and her team from the University of Michigan used "in-depth interviews [to] assess participants' perspectives on their interactions" to discover how lived experiences, such as growing up during the Cultural Revolution, influence Chinese grandparenting styles. ${ }^{21}$ Furthermore, Fei Hsiu Hsiao, assistant professor at Taipei Medical University, and her team conducted 28 interviews with Chinese-Australian patients and their caregivers to further understand mental health suffering in

\footnotetext{
${ }^{16}$ Hille, Kathrin. “China’s 'Sent-Down’ Youth.” FinancialTimes, 20 Sept. 2013, www.ft.com/content/3d2ba75c1fdf-11e3-8861-00144feab7de.

${ }^{17}$ Gao, Mobo C. F. "Debating the Cultural Revolution: Do We Only Know What We Believe?" Critical Asian Studies, vol. 1, no. 3, 9 Nov. 2010, pp. 419-434. https://www.researchgate.net/publication/233325301_Debating_the_Cultural_Revolution_Do_We_Only_Know_What_We_Believe

${ }^{18}$ Kanbur, Ravi, and Xiaobo Zhang. "Fifty Years of Regional Inequality in China: A Journey through Revolution, Reform and Openness." SSRN, 2021, papers.ssrn.com/sol3/papers.cfm?abstract_id=278564.

${ }^{19}$ Schwandt, T. A., \& Gates, E. F. (2018). Case Study Methodology. In N. K. Dezin \& Y. S. Lincoln (Eds.), The SAGE Handbook of Qualitative Research (5th ed.; pp. 341-358). Thousand Oaks, CA: SAGE.

${ }^{20}$ Baxter, P., \& Jack, S. (2008). Qualitative Case Study Methodology: Study Design and Implementation for Novice Researchers. The Qualitative Report, 13(4), 544-559. https://nsuworks.nova.edu/tqr/vol13/iss4/2/.

${ }^{21}$ Nagata, D. K., Cheng, W. J. Y., \& Tsai-Chae, A. H. (2010). Chinese American grandmothering: A Qualitative Exploration. Asian American Journal of Psychology, 1(2), 151-161. https://doi.org/10.1037/a0019963.
} 
Chinese society. Hsiao's study parallels the current research question as it attempts to synthesize subjective experiences in view of cultural values, such as "the influence of [contemporary] Confucian ideals", in order to reach a greater "understanding [regarding] the complex roles underpinning interpersonal behaviors in Chinese culture". ${ }^{22}$ These studies show the prevalent use of conducting interviews and thematic analysis in research questions concerning the impact of shared cultural experiences and values on individual reflections, thus aligning this methodology with this research goal.

Although I began my research with the intent of conducting all interviews personally, I found that it was not feasible due to the method of selection for participants needed for the study. During the outreach process which employed social media platforms, namely Facebook and LinkedIn, I realized the majority of my participants had very similar geopolitical backgrounds. This is most likely due to the fact that I only had resources to contact potential participants who lived in the United States and had access to American social media, leading to a lack of diversity in sampling. This would ultimately skew the results of my study. To maintain an unbiased perspective, I decided to redirect my focus to utilizing existing collections of interviews, provided by universities or research groups.

\section{Database Selection}

Several databases were considered for evaluation including collections from the University of North Carolina Chapel Hill Libraries and Gale Academic OneFile. Ultimately, the Cultural Revolution: 10 database (CR/10), an oral history project sponsored by the University of Pittsburgh, was selected. It features over 10 independent interviewers/creators, including the University of Pittsburgh University Libraries, with the collection of interviews beginning in December of 2015 under Haihui Zhang, Head of the East Asian Library at the University of Pittsburgh. ${ }^{23}$ The database continues to be updated regularly: the latest interviews were added in 2020.

There were three main reasons why this particular database was selected. Firstly, in these interviews, participants specified the region they lived in during their participation in the Educated Youth Program. This directly addresses one of the key gaps identified by ensuring that a wide range of locations would be represented in the research. Furthermore, the database featured multiple verified interviewers, not all employed under the University of Pittsburgh, providing both credibility and variability. Lastly, the most important reason why the CR/10 database was the best selection for this research was due to its use of free-association narrative interviews, which are defined as in-depth semi-structured interviews that provide flexibility to answer multi-dimensional questions. ${ }^{24}$ As stated by Dr. David Stokes, professor at the University of Washington Seattle, this style of interview demonstrates "the ability to get under the surface", especially when dealing with personal topics, a crucial component to answering my research question. ${ }^{25}$ As opposed to written questionnaires, these short interviews allowed for participants to highlight the experiences they deemed were most important to share. The participants were given only two guiding questions for these interviews:

Please briefly discuss the age and province you were at during the Cultural Revolution.

Share with the audience your deepest impression of the Cultural Revolution.

\footnotetext{
${ }^{22}$ Hsiao, Fei-Hsiu, et al. "Cultural Attribution of Mental Health Suffering in Chinese Societies: The Views of Chinese Patients with Mental Illness and Their Caregivers." Journal of Clinical Nursing, vol. 15, no. 8, Aug. 2006, pp. 998-1006, onlinelibrary.wiley.com/doi/abs/10.1111/j.1365-2702.2006.01331.x, 10.1111/j.1365-2702.2006.01331.x.

23 “CR/10 (Cultural Revolution: 10).” Pitt.Edu, 2017, culturalrevolution.pitt.edu/\#intro.

${ }^{24}$ Stokes, David. “Conservators of Experience.” ResearchGate, Oxford University Press (OUP), 19 Jan. 2009 , www.researchgate.net/publication/232661530_Conservators_of_Experience.

${ }^{25}$ Ibd., 7.
} 


\section{Interview Selection}

Due to the fact the $\mathrm{CR} / 10$ database contains a total of 107 interviews, I found it necessary to narrow down my results to those which pertain to my research question. To begin this process, I looked for key terms in the interview's title, description, and subject. The results from the preliminary selection are shown below:

Table 1: Number of Interviews under Key Term

\begin{tabular}{|l|l|}
\hline Key Term: & Number of Relevant Interviews: \\
\hline Educated Youth & 22 \\
\hline "Up the Mountains, Down the Countryside" & 5 \\
\hline School & 17 \\
\hline Total & 44 \\
\hline
\end{tabular}

After identifying this selection of relevant interviews and then accounting for interviews that appeared under more than one key term, there were a total of 32 interviews that I could incorporate. Due to the fact that each interview was 10-15 minutes long, I concluded that 12 interviews would contain enough information for me to form a strong conclusion. Thus, I decided to form additional guidelines for interview selection. All interviews would ideally focus on participants of the program that stayed for a long duration of time, seeing that they would have the most profound memories of the program. This was done by looking at the age/birthdate of the interviewee; those born around the 1950s would have entered the Educated Youth Program as it started, therefore participating for most of their adolescent education. Furthermore, I decided to choose my interviews through stratified sampling in order to ensure regional diversity within my study. This sampling strategy involves the use of subpopulations in deriving samples to better reflect the general population "while maintaining essential properties of the data set". ${ }^{26}$ Interviews were generally divided along regional lines into three groups: north, south, and central China. I then utilized an online stratified sampling calculator to determine my final list. The 12 interviews and their corresponding identifiers can be seen in Table 2. The last three letters of each identifier specify the location of the participant through romanized abbreviations; for example, BEJ would indicate that the participant is from Beijing.

\section{Thematic Analysis}

After the selection of data, the next step of the methodology was to conduct thematic analysis. The primary goal of conducting thematic analysis is to discover trends and relationships in data by finding overarching themes and developing specific ideas "into increasingly more abstract units of information". ${ }^{27}$ While English translations were provided by the University of Pittsburgh, I also watched the original interviews that were conducted in Mandarin Chinese in order to consider the manner in which the interviewee conveyed their words. Although some participants also discussed the impacts that the Cultural Revolution had on their immediate families or the changes they witnessed in

${ }^{26}$ Meng, Xiangrui. "Scalable Simple Random Sampling and Stratified Sampling." Proceedings of the 30th International Conference on Machine Learning, Proceedings of Machine Learning Research, 2013, pp. 531-539, proceedings.mlr.press/v28/meng13a.pdf.

${ }^{27}$ Creswell, John W. Research Design: Qualitative, Quantitative, and Mixed Methods Approaches. Thousand Oaks, CA: SAGE Publications, 2014. 
siblings as a result of the Educated Youth Program, such experiences were not considered in the findings. Only the most accurate reflections, personal experiences and feelings, were considered for analysis.

During the initial readthrough, passages which directly answered the research question were underlined. Furthermore, I noted trends that repeatedly appeared in the interviews. More extensive examination was then conducted on the underlined portions. Different colors highlight which theme the passage belongs to and bolded keywords indicate my reasoning behind these placements; Figure 1, below, provides an example of how I did so. Keywords were necessary as interviews had to be assessed multiple times to verify that justifications were consistent throughout the analysis process. Ideas that were lacking in relevance were disregarded and similarly, overlapping ideas were merged into more concrete themes.

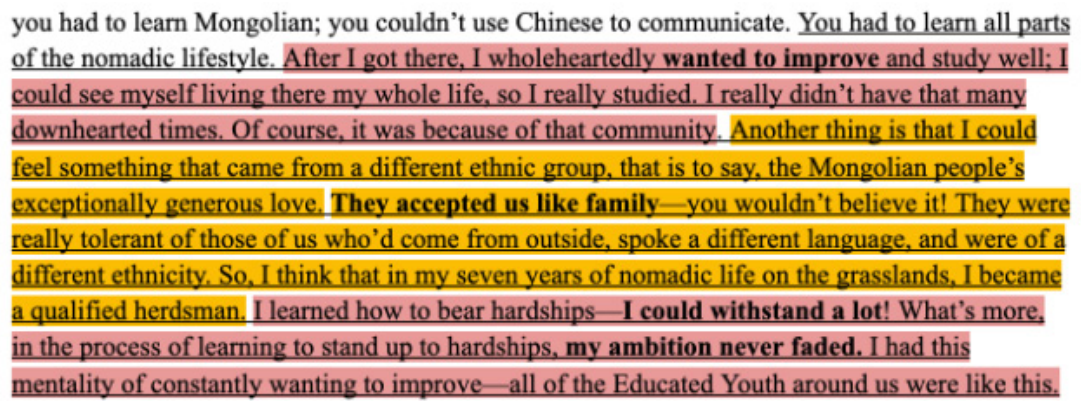

Figure 1: CR10-0025-BEJ Transcribed Excerpt

\section{Findings}

\section{Definitions}

Two main components to my thematic analysis corresponded with the two aspects of my research question: identifying the impacts and determining whether or not they are positive. To begin, I outlined three areas of focus that were repeatedly spoken about throughout all the interviews. These categories served as more general guidelines for me to place interviews, answering the first aspect of my research question by identifying several immaterial impacts. The categories are defined below:

Table 3: Categories Defined

\begin{tabular}{|l|l|}
\hline Category & Definition \\
\hline Finding Strength & $\begin{array}{l}\text { The participants found a form of inner strength due to the experiences of the rural } \\
\text { education. }\end{array}$ \\
\hline Attitude Towards Others & $\begin{array}{l}\text { The Educated Youth Program impacted the participant's understanding of others that } \\
\text { are different }\end{array}$ \\
\hline $\begin{array}{l}\text { Sentiments on Life Opportu- } \\
\text { nities }\end{array}$ & $\begin{array}{l}\text { Participant's perspective changed about the opportunities available and possible to } \\
\text { achieve for them. }\end{array}$ \\
\hline
\end{tabular}

In order to answer the second part of my research question, whether the impacts were positive or negative, I broke down each category into two themes, one meant to represent a positive interpretation while the other negative. These themes allowed me to further narrow my conclusions. For example, in the category Finding Strength, 
Perseverance is defined as helpful character growth which contrasts with the negative interpretation, Adaptability (defined as forced character growth). Six themes are defined below:

Table 4: Themes Defined

\begin{tabular}{|c|c|c|}
\hline Category & Theme & Definition \\
\hline \multirow{2}{*}{$\begin{array}{l}\text { Finding } \\
\text { Strength }\end{array}$} & Perseverance & $\begin{array}{l}\text { Participants discovered helpful character growth } \\
\text { which was beneficial to their life and attaining } \\
\text { their goals. }\end{array}$ \\
\hline & Adaptability & $\begin{array}{l}\text { Participants underwent forced character growth in } \\
\text { unfamiliar circumstances which was seen as a } \\
\text { trauma response. }\end{array}$ \\
\hline \multirow{2}{*}{$\begin{array}{l}\text { Attitude To- } \\
\text { wards Others }\end{array}$} & $\begin{array}{l}\text { Acceptance of Oth- } \\
\text { ers }\end{array}$ & $\begin{array}{l}\text { Positive impressions regarding collectivism for } \\
\text { people of different socioeconomic and geographic } \\
\text { background }\end{array}$ \\
\hline & $\begin{array}{l}\text { Division from Oth- } \\
\text { ers }\end{array}$ & $\begin{array}{l}\text { Negative impressions regarding collectivism for } \\
\text { people of different socioeconomic and geographic } \\
\text { background }\end{array}$ \\
\hline \multirow{2}{*}{$\begin{array}{l}\text { Sentiments on } \\
\text { Life Opportu- } \\
\text { nities }\end{array}$} & $\begin{array}{l}\text { Opportunities Were } \\
\text { Provided }\end{array}$ & $\begin{array}{l}\text { Participants saw their goals as more attainable for } \\
\text { them. }\end{array}$ \\
\hline & $\begin{array}{l}\text { Opportunities Were } \\
\text { Taken }\end{array}$ & $\begin{array}{l}\text { Participants saw their goals as less attainable for } \\
\text { them. }\end{array}$ \\
\hline
\end{tabular}

\section{Summaries}

To organize my overall findings, each interview was arranged with its corresponding theme and justification. Table 5, shown below, utilizes key events from the interviews in order to summarize the personal perspectives held by participants. Column one indicates the interview identifier, utilized previously for stratified sampling, to identify the interview used. The second column contains a short summary of the interviewee's experiences and which category these experiences relate to. Multiple interviews justified placements in more than one category, demonstrating both the wide range of experiences that many participants had and the depth of these interviews. Finally, the third column evaluates whether these experiences were shown to be or implied as positive or negative, placing them into a theme within the indicated category. The table highlighted which of the themes were most recurring, and consequently most significant.

Table 5: Summaries for 12 Narrative Interviews

\begin{tabular}{|l|l|l|}
\hline $\begin{array}{l}\text { Interview } \\
\text { Identifier }\end{array}$ & $\begin{array}{l}\text { Reflections on (1) Finding Strength, (2) Attitude Towards Others, and (3) Senti- } \\
\text { ments on Life Opportunities }\end{array}$ & Themes Present \\
\hline $\begin{array}{l}\text { CR10- } \\
0081-H L J\end{array}$ & $\begin{array}{l}\text { (1) Despite hard work, described it as a relatively happy time, learned "how to persist } \\
\text { in the face of adversity" }\end{array}$ & Perseverance \\
\hline $\begin{array}{l}\text { CR10- } \\
\text { 0078-SHD }\end{array}$ & $\begin{array}{l}\text { (1) Lived by the countryside for three years and found encouragement from those } \\
\text { around them, benefitted from the "mindset of peasants" }\end{array}$ & Perseverance \\
\hline
\end{tabular}




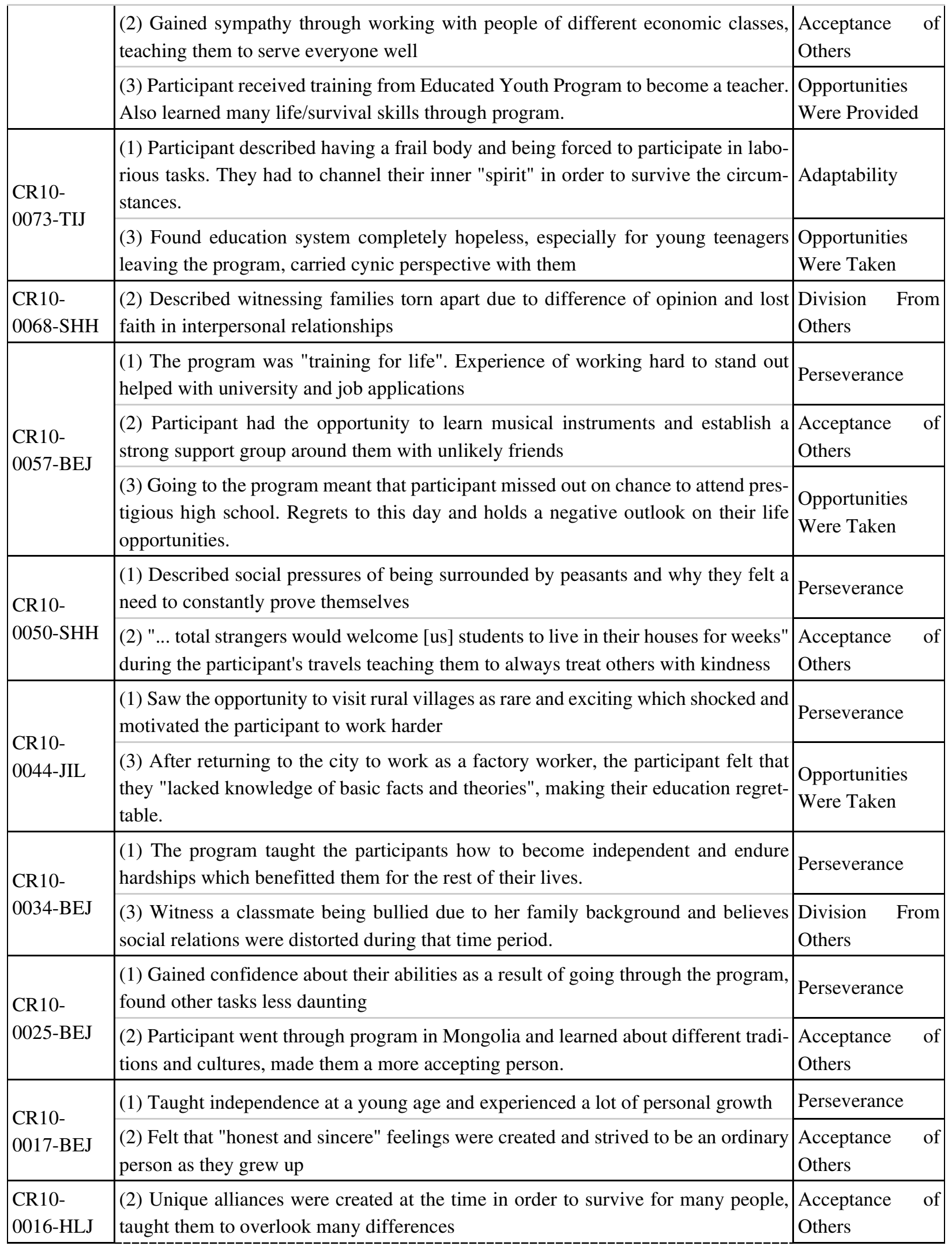




\begin{tabular}{|l|l|l|}
\hline & $\begin{array}{l}\text { (3) Participant states how they would "give back to local enterprises" where they } \\
\text { spent their youth and how this grew into unique business spheres }\end{array}$ & $\begin{array}{l}\text { Opportunities } \\
\text { Were Provided }\end{array}$ \\
\hline CR10- & $\begin{array}{l}\text { (2) Participant had a "bad background" and was isolated from classmates, did not } \\
\text { have strong connections with others growing up }\end{array}$ & $\begin{array}{l}\text { Division } \\
\text { Others }\end{array}$ \\
\hline 0014-LIN & $\begin{array}{l}\text { (3) Participant was also held back from joining many group activities, felt as if they } \\
\text { are lacking when they grew up }\end{array}$ & $\begin{array}{l}\text { Opportunities } \\
\text { Were Taken }\end{array}$ \\
\hline
\end{tabular}

\section{Results}

The next step was to compile this data into a strong conclusion. It was clear that some categories were more widely held than others by participants across geographic locations, as seen in Table 5. To demonstrate my results, I began transforming my qualitative data into more comparable quantitative data. This was done by indicating all the interviews which belonged under a particular theme as seen below:

Table 6: Interviews by Theme

\begin{tabular}{|c|c|c|c|}
\hline Category & Theme & Interviews & $\begin{array}{l}\text { To- } \\
\text { tal }\end{array}$ \\
\hline \multirow[t]{2}{*}{ Finding Strength } & Perseverance & $\begin{array}{l}\text { CR10-0081-HLJ, CR10-0078-SHD, CR10-0057-BEJ, CR10- } \\
\text { 0050-SHH, CR10-0044-JIL, CR10-0034-BEJ, CR10-0025- } \\
\text { BEJ, CR10-0017-BEJ }\end{array}$ & 8 \\
\hline & Adaptability & CR10-0073-TIJ & 1 \\
\hline \multirow{2}{*}{$\begin{array}{l}\text { Attitude Towards } \\
\text { Others }\end{array}$} & $\begin{array}{ll}\text { Acceptance of } \\
\text { Others }\end{array}$ & $\begin{array}{l}\text { CR10-0078-SHD, CR10-0057-BEJ, CR10-0050-SHH, CR10- } \\
\text { 0025-BEJ, CR10-0017-BEJ, CR10-0016-HLJ }\end{array}$ & 6 \\
\hline & $\begin{array}{l}\text { Division from } \\
\text { Others }\end{array}$ & CR10-0068-SHH, CR10-0034-BEJ, CR10-0014-LIN & 3 \\
\hline \multirow{2}{*}{$\begin{array}{l}\text { Sentiments on Life } \\
\text { Opportunities }\end{array}$} & $\begin{array}{l}\text { Opportunities } \\
\text { Were Provided }\end{array}$ & CR10-0078-SHD, CR10-0016-HLJ & 2 \\
\hline & $\begin{array}{l}\text { Opportunities } \\
\text { Were Taken }\end{array}$ & $\begin{array}{l}\text { CR10-0073-TIJ, CR10-0057-BEJ, CR10-0044-JIL, CR10- } \\
\text { 0014-LIN }\end{array}$ & 4 \\
\hline
\end{tabular}

To determine the significance of these categories and themes, bar graphs were created, allowing the data to be more easily compared. Figure 2 depicts the most significant categories as Finding Strength and Attitude Towards Others. In Figure 3, it can be seen that in both these categories the positive interpretations were far more popular with the opposite being true for the category Sentiments on Life Opportunities. The least applicable theme was Adaptability, with only one interview referencing it. 


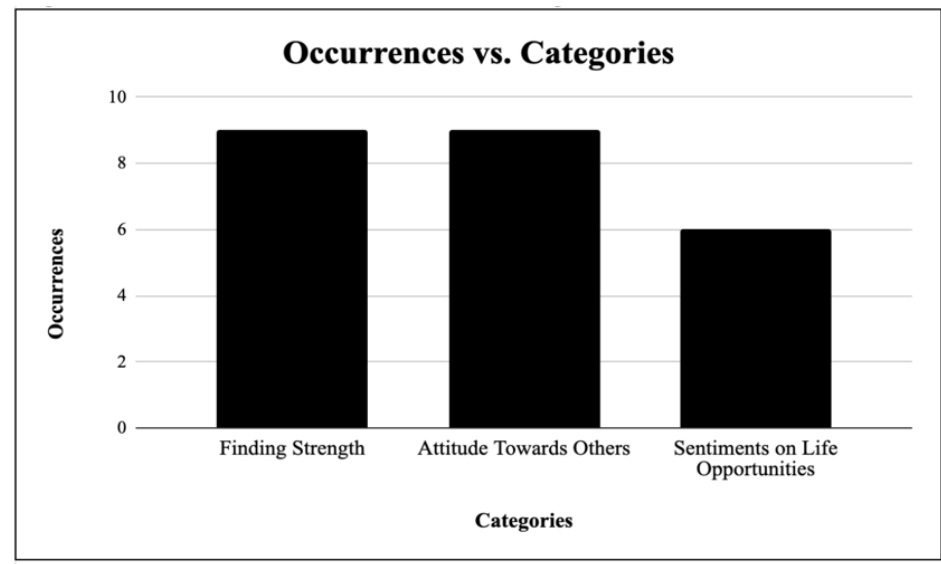

Figure 2: Number of Occurrences in Interviews vs. Categories

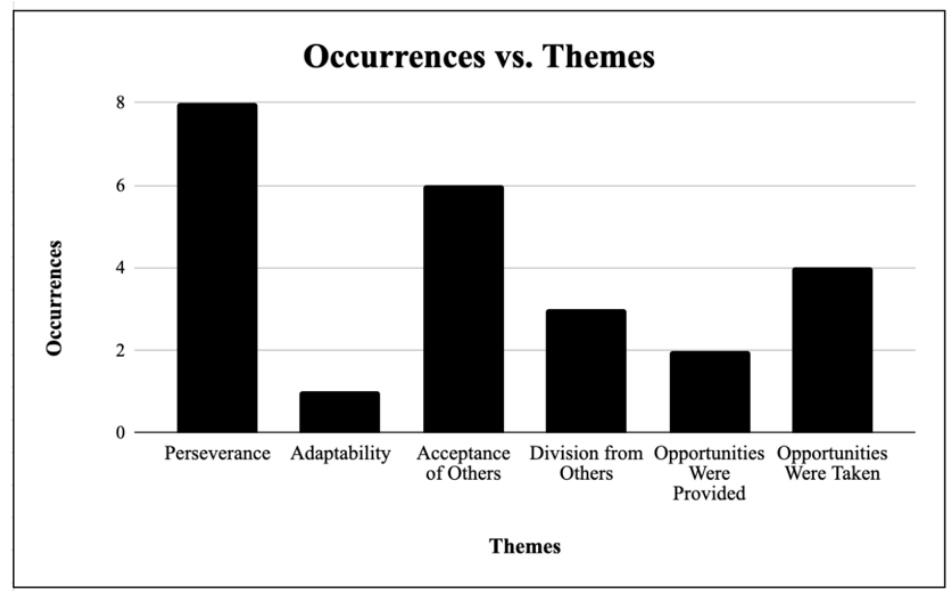

Figure 3: Number of Occurrences in Interviews vs. Themes

\section{Discussion}

The narrative interviews demonstrated the varying immaterial impacts that the Educated Youth Program had on its participants. Although there was a total of six themes, my findings only indicated the significance of two major themes, Perseverance and Acceptance of Others, each impacting half or more of the participants. These two themes shed light on the most prevalent feelings that interviewees carry with them from their rural education. Although the themes stem from different categories, both served as positive interpretations indicating that the immaterial impacts of the Educated Youth Program were positive overall.

\section{Recurring Theme 1: Perseverance}

The most prevalent theme among interviewees was the perspective that the Educated Youth Program helped influence the participant's perseverance. As mentioned earlier, Perseverance is the positive interpretation of the category Finding Strength, focusing on character growth. This theme, as outlined by Table 4, is defined as finding inner strength that the participant did not have or recognize prior to this experience which they found useful in their life-long 
challenges. These participants not only regarded this acquisition as a positive, some even expressed that they would enroll their children in similar experiences in hopes of giving them the same impact.

Of the twelve interviews, eight acknowledged that the Educated Youth Program had a strong and lasting influence on the participant's ability to persevere. This adds to the existing body of research as it generally supports the underlying theme of human resilience as discussed by Professor Yu Xie and his team from the University of Michigan. However, there is an important difference to note between how "human resilience" is defined in previous literature and how Perseverance is defined. While previous research had identified and defined "human resilience" as, "find[ing] ways to adapt and thus avoid lasting harm", Perseverance does not recognize the latter half of the definition, to "avoid lasting harm", as inner strength was not seen as a mechanism for survival. In fact, this aspect of "human resilience" may be interpreted as more aligned with the theme Adaptability, the negative interpretation of Finding Strength. This may explain why this category was the most prevalent of the three, with a total of nine relevant interviews, seeing that it comprehensively captured an idea previously supported through quantitative research. These results, in part, help further narrow down the previously established definition of "human resilience", with eight out of nine participants particularly resonating with one aspect of the definition through the theme Perseverance.

Many participants described how being around peasants and in the countryside inadvertently inspired them to also work harder. Interviewee, CR10-0050-SHH, reflects, "Peasants worked arduously, in fact. So, you had to be the same as them... to prove that you could endure the same difficulties as them". The sudden shift in the environment created a different milieu for these participants, changing their role models and who they derived support from. Therefore, students felt the unconscious need to fit in, motivating them to persevere in harsh circumstances. Witnessing the lives of those less fortunate in rural landscapes, showed the participants in the Educated Youth Program, who mainly grew up in urban cities, that what they viewed as difficult tasks were actually daily chores for many people.

Furthermore, Participant CR10-0044-JIL, outlines how the unique circumstances of the Educated Youth Program gave rise to social pressures that would not have been achieved under traditional education curriculums, mentioning how "[they] answered the call and went to the rural villages to join production teams and organize collective households... and ... tried to outdo one another". Given the freedom to pursue more responsibilities through rural education, participants felt as if they were expected to handle more. Many of these students had no understanding of rural villages and lives outside of their own before these immersions and thus gained a new understanding of strength after interacting with their environment. The Educated Youth Program for a large majority of its participants became a support group that inspired students to work harder than before. In their interview CR10-0025-BEJ, summarizes these thoughts by stating, "I had this mentality of constantly wanting to improve - all of the Educated Youth around us were like this". This again validates the idea that group mentality in the program supported participants in finding personal strength. These recallings provide strong evidence that a majority of participants were able to cultivate motivation through the Educated Youth program to display greater perseverance.

\section{Recurring Theme 2: Acceptance of Others}

The second major theme, Acceptance of Others is also a positive interpretation, for the category Attitude towards Others, which states that participants worked better with others as a result of their experiences. The definition, as provided by Table 4, explains the theme of Acceptance of Others specifically as feeling a strong connection towards the message of collectivism, especially when regarding individuals of different backgrounds. It is important to note that this theme manifested itself in two main ways for the participants: impressions of those from different economic classes and impressions of those from different ethnic backgrounds.

Of the twelve interviews, half identified this collectivism as an impact of the Educated Youth Program. It is important to note that while this immediate category had the same level of response as Finding Strength (containing Perseverance), with nine responses, there was greater variation among the themes within Attitude towards Others with three of the responses falling under Division from Others, and only six responses supporting Acceptance of Others, compared to the eight for Perseverance. Furthermore, another striking observation is that this theme does not 
directly connect to any of the literature explored previously in this paper. It can be assumed that since the existing field of research has mainly utilized quantitative measures such as employment rate and salaries, feelings towards different types of people are unlikely to be considered as a variable by most researchers. This theme can prove to be useful in future correlational research, allowing a more comprehensive view of the constitution of the "lost" generation.

As mentioned previously, there were two main ways this theme could be observed in participants. In participant CR10-0025-BEJ's interview, they discuss how the Educated Youth Program impacted their understanding of different ethnic groups. They specifically delve into their relations with the Mongolian nomads that they spent their formative years with, mentioning that regardless of the ethnic differences between them, "[Mongolians] accepted us like family". CR10-0025-BEJ demonstrates how these interactions helped them recognize "friendlier associations between ethnic group[s]". The long-lasting impression of these groups shows how these impressions carried into adulthood, having possible implications for other relationships and connections. Similarly, CR10-0016-HLJ describes how participants from "Harbin, Beijing, Shanghai, and Hangzhou, [urban cities]... got along with the local people very well"; even more indicative of this theme is how students "gave local cultural enterprises a lot of help" as the program was paused. Participants gained a certain level of appreciation to those around them due to the events of the Educated Youth Program, and as a result, fostered lasting relationships with unique persons. As seen in the example of helping local enterprises, these relationships had significant impacts on the decisions participants made, even after the Cultural Revolution.

The second way the theme is observed, through interactions of those from different economic classes, is recounted by CR10-0078-SHD and their experience of learning to gain sympathy for those less wealthy. They state that "my feelings toward [peasants] have remained the same since [the program]... I will serve [my] people well today and in the future". It is clear that the participant considers those of all economic classes equally and as one group, seeing peasants as their "people" as well. This suggests a stronger acceptance of differences and divisions as a result of the Educated Youth Program, as the interviews outline direct action that is a result of participants' influenced perspectives. In conclusion, it is clear that going through an alternative education has directed some to be more encompassing of those around them, leading to a wider range of interpersonal relationships.

\section{Limitations}

To fully understand the scope and conclusions of these results, it is important to account for the limitations of this study, mainly those concerning methodology, which may impact the generalizability and accuracy of this research. Firstly, due to the fact that all the interviews were collected through one database, these results may be impacted by sampling bias. The second key limitation concerns the manner in which thematic analysis was conducted in this paper. Typically, multiple researchers are expected to be involved in identifying and categorizing interviews in order to mitigate personal biases. This was not feasible for this study, however, and thus the categories and themes established in the paper are subject to personal bias. Finally, as with all ethnographic research, it is impossible to truly capture an entire demographic's attitude towards a subject through the study of a limited sample. These results may be less generalizable due to the amount of data that was analyzed.

\section{Conclusion}

After exploring the long-term impacts of the Educated Youth Program, it is clear that there are many influences of such rural education that participants carry with them into adulthood. Although several categories such as Finding Strength, Attitude towards Others, and Impact on Opportunities stood out throughout the selected interviews, it is important to note the clear distinction between those who viewed these changes in a positive light in contrast to those who saw these as mainly negative. The most prominent and conclusionary themes were the ideas of Perseverance and 
Acceptance of Others. This indicates that participants in the Educated Youth Program found it easier to navigate through different challenges in their life due to this experience. Furthermore, the study suggests that those who went through the program became more accepting of others coming from different ethnic and economic backgrounds. The findings of this research support my original hypothesis considering both significant themes were positive. Ultimately, participants found that the impacts of the Educated Youth Program were largely positive despite the regrettable circumstances of the Chinese Cultural Revolution.

\section{Implications}

These findings, through the incorporation of free-association narrative interviews, bring greater attention to the personal perspectives of those involved in not only the Educated Youth Program but the Chinese Cultural Revolution as a whole. This study demonstrates the ability of qualitative research to supplement the existing body of literature as well as provide new insights into the topic. These results suggest that future researchers may benefit from utilizing more mixed methods in their historical studies in order to gain the most comprehensive understanding of the past. Furthermore, the findings warrant future discussions regarding the relationship between the physical and abstract impacts felt by the participants of the Educated Youth Program, as discussed with the theme Acceptance of Others. As the research reveals, the same group of participants often experience more than one of these impacts, making it likely that correlational studies will be able to discover exciting new trends among these impacts. While quantitative research has identified several isolated impacts of the Educated Youth Program, more in-depth qualitative studies with longer interviews and more participants can help the research field explain these differences.

This relates to the second implication, a greater understanding regarding the generational cohort involved in the Chinese Cultural Revolution - namely those born in the 1950s — as a whole. With the aging population in China, the elderly make up a large portion of the current population. Learning about their lived experiences and what makes their generation unique will allow the community to more easily support them as a whole.

This study has proved thematic analysis of interviews as a feasible manner in identifying immaterial impacts. Future researchers may choose to utilize this methodology in order to focus on identifying more specific immaterial impacts beginning with further narrowing the themes established in this study. These findings about the Educated Youth Program will lead to learning more about what this generation feels as if they are lacking and what they value as a result of it. This can help future generations better understand how to help those who went through the program with the resources at hand.

Lastly, this research gives insight into the concept of rural education. As previously stated, the Educated Youth Program is the only instance of sustained large-scale rural education. With the focus and need for education in society greater than ever, research into non-traditional forms of education can provide information on how society can further improve the current education system. This study mainly suggests that there are benefits to considering incorporating some aspects of rural education into various schooling systems. By demonstrating the potential benefits of the environment in which the Educated Youth Program took place, researchers are encouraged to explore curriculums outside of the traditional classroom to benefit future students. Due to the specific and limited subjects explored in this study, further research done with participants under a broader demographic will allow more generalizable conclusions about rural education as a whole.

In conclusion, this academic paper makes the use of a unique methodology — specifically, free-association interviews - to investigate a research field that is typically guided by quantitative values and government data. By doing so, it reevaluates and draws new understandings about the impacts of the Educated Youth Program on its participants.

\section{Acknowledgments}

I would like to thank Kathryn Upton for helping me with this project. 


\section{References}

Baxter, P., \& Jack, S. (2008). Qualitative Case Study Methodology: Study Design and Implementation for Novice Researchers. The Qualitative Report, 13(4), 544-559. TheQualReport, doi: 10.46743/21603715/2008.1573.

Bennett, Gordon. "Up to the Mountains and Down to the Villages: The Transfer of Youth from Urban to Rural China. By Thomas P. Bernstein. [New Haven and London: Yale University Press, 1977. 371 Pp. \$17.50. $£ 12$.60.].” The China Quarterly, vol. 75, 1978, pp. 660-66, doi:10.1017/S0305741000042624.

Chen, Yixin. "Lost in Revolution and Reform: The Socioeconomic Pains of China's Red Guards Generation, 19661996.” Journal of Contemporary China, vol. 8, no. 21, 2013, pp. 219-239, doi:10.1080/10670569908724345.

“CR/10 (Cultural Revolution: 10).” Pitt.Edu, 2017, culturalrevolution.pitt.edu/\#intro.

Creswell, John W. Research Design: Qualitative, Quantitative, and Mixed Methods Approaches. Thousand Oaks, CA: SAGE Publications, 2014. http://www.drbrambedkarcollege.ac.in/sites/default/files/ResearchDesign_Qualitative-Quantitative-and-Mixed-Methods-Approaches.pdf.

Deng, Zhong, and Donald J. Trieman. "The Impact of the Cultural Revolution on Trends in Educational Attainment in the People's Republic of China.” The American Journal of Sociology, vol. 103, no. 2, 15 Feb. 2013, pp. 391-428. The University of Chicago Press Journals, doi: 10.1086/231212.

Ebrey, Patricia Buckley (2005). China: A Cultural, Social, and Political History (1st ed.). Wadsworth Publishing. p. 294. ISBN 978-0618133871.

Fan, Wen. "Children of the Chinese Cultural Revolution: Disrupted Education, Send-Down Experiences, and Subsequent Health.” Conservancy.UHN, University of Minnesota Digital Conservancy, June 2015, http://conservancy.umn.edu/handle/11299/175433.

Gao, Mobo C. F. "Debating the Cultural Revolution: Do We Only Know What We Believe?" Critical Asian Studies, vol. 1, no. 3, 9 Nov. 2010, pp. 419-434. Taylor and Francis Online, doi: 10.1080/1467271022000008956.

Hille, Kathrin. “China's 'Sent-Down' Youth.” FinancialTimes, 20 Sept. 2013, www.ft.com/content/3d2ba75c-1fdf11e3-8861-00144feab7de.

Hsiao, Fei-Hsiu, et al. "Cultural Attribution of Mental Health Suffering in Chinese Societies: the Views of Chinese Patients With Mental Illness and Their Caregivers." Journal of Clinical Nursing, vol. 15, no. 8, 2006, pp. 998-1006.

Hyman, H. H., \& Wright, C. R. (1979). Education's Lasting Influence on Values. American Journal of Education, 88(1), 113-119. doi:10.1086/443505.

Kanbur, Ravi, and Xiaobo Zhang. "Fifty Years of Regional Inequality in China: A Journey through Revolution, Reform and Openness." SSRN, 2021, papers.ssrn.com/sol3/papers.cfm?abstract_id=278564.

Meng, Xiangrui. “Scalable Simple Random Sampling and Stratified Sampling." Proceedings of the 30th International Conference on Machine Learning, Proceedings of Machine Learning Research, 2013, pp. 531-539, proceedings.mlr.press/v28/meng13a.pdf.

Nagata, D. K., Cheng, W. J. Y., \& Tsai-Chae, A. H. (2010). Chinese American grandmothering: A Qualitative Exploration. Asian American Journal of Psychology, 1(2), 151-161. doi:10.1037/a0019963.

Schwandt, T. A., \& Gates, E. F. (2018). Case study methodology. In N. K. Dezin \& Y. S. Lincoln (Eds.), The SAGE Handbook of Qualitative Research (5th ed.; pp. 341-358). Thousand Oaks, CA: SAGE.

Stokes, David. “Conservators of Experience.” ResearchGate, Oxford University Press (OUP), 19 Jan. 2009, www.researchgate.net/publication/232661530_Conservators_of_Experience.

Walder, Andrew G, and Yang Su. "The Cultural Revolution in the Countryside: Scope, Timing and Human Impact." The China Quarterly, no. 173, 2003, pp. 74-99. JSTOR, www.jstor.org/stable/20058959?seq=1.

Xie, Yu, et al. "Did Send-down Experience Benefit Youth? A Reevaluation of the Social Consequences of Forced 
Urban-Rural Migration during China's Cultural Revolution." Social Science Research, vol. 37, no. 2, June 2008, pp. 686-700. National Center for Biotechnology Information, www.ncbi.nlm.nih.gov/pmc/articles/PMC2597845/.

Yihong, Pan. "An Examination of the Goals of the Rustication Program in the People's Republic of China." Journal of Contemporary China, vol. 11, no. 31, 2 Aug. 2010, pp. 361-379. Taylor and Francis Online, doi: 10.1080/10670560220129667.

Zhou, Weina. "How Does a Traumatic Experience During Youth Affect Life Later? The Long-Term Impact of the Send-Down Program During the Chinese Cultural Revolution." Semantic Scholar, DalHousie University, August 2013, pp. 4. https://www.semanticscholar.org/paper/How-Does-a-Traumatic-Experience-DuringYouth-Affect-Zhou/733526af03caa40a16094da74437fffade096c84

Zhou, Xueguang, and Liren Hou. "Children of the Cultural Revolution: The State and the Life Course in the People's Republic of China.” American Sociological Review, vol. 64, no. 1, February 1999, pp. 12-36. JSTOR, doi: 10.2307/2657275. 